



\title{
Ensayo
}

\section{Lo indio, indigenismo y movimiento campesino en el Perú}

\author{
The Indian, the indigenous and the peasant $\mathbf{O}$ índio, indigenismo e movimento \\ movement in Peru \\ campesino no Peru
}

\section{Carlos Fernández Fontenoy (Perú)}

Universidad Nacional Mayor de San Marcos.

cfernandez1956@yahoo.es

Doctor en Ciencia Política y Sociología por la Universidad

Complutense de Madrid.

\section{Resumen}

En este artículo el autor presenta un análisis histórico sobre la naturaleza de la aparición de movimientos indígenas en Perú, en la segunda mitad del siglo XX. Se compara la situación del país andino, con otros de la región y encuentra una relación con las especiales condiciones en las que se conforman los partidos políticos y se describe su dependencia con los movimientos sociales y campesinos.

\begin{abstract}
In this article the author presents a historical analysis of the nature of the emergence of indigenous movements in Peru in the second half of the twentieth century. He compares the situation in this Andean country, with others in the region and finds a relationship with the special conditions under which political parties are formed and describes its dependence on social and peasant movements.
\end{abstract}

\section{Resumo}

Em este artigo o autor apresenta uma análise histórica sobre a natureza da aparição de movimentos indígenas no Peru, na segunda metade do século XX. Compara-se a situação do país andino, com outros da região e encontra uma relação com as especiais condições nas que se conformam os partidos políticos e descreve-se a sua dependência com os movimentos sociais e campesinos.
Keywords: social movements, indigenous, Perú, peasants, political parties
Palabras clave: Movimientos sociales, indígenas, Perú, campesinado, partidos políticos.
Palavras chave: Movimentos sociais, indígenas, Peru, movimento campesino, partidos políticos.

\section{Para citar este artículo / To cite this article / Para citar este artigo}

Fernandez, C. (2013). Lo indio, indigenismoy movimiento campesino en el Perú. Panoarama (VII) 12189 - 208. 

Una de las preguntas recurrentes que se formulan los estudiosos de los movimientos indígenas de la región andina, se refiere a las causas de la inexistencia en el Perú —en la segunda mitad del siglo XX - de importantes movimientos indígenas que reivindiquen no sólo su identidad, sino una serie de derechos propios a las naciones o nacionalidades oriundas, como son, por ejemplo, el derecho a una educación bilingüe o a un territorio determinado.

Mientras en Bolivia, a partir de 1970 se iniciaban movimientos reivindicativos de identidades y derechos étnicos como los movimientos katarista e indianista (Calla, 1993) cuyos discursos lograron penetrar y hacerse un espacio en los programas de gobierno de varias organizaciones políticas; en Perú se iniciaba un proceso de colectivización del agro, formando cooperativas en la Costa y reafirmando y legalizando a las comunidades indígenas de la Sierra y a las nativas de la Selva.

Cuando en 1986 se estaba fundando la Confederación de Nacionalidades Indígenas del Ecuador (CONAIE), el Perú ya se estaba convirtiendo en un campo de batalla en el cual, los campesinos -indígenas y mestizos- eran reclutados muchas veces a la fuerza, ya sea por el Ejército Popular de Sendero Luminoso o por las Fuerzas Armadas del Estado peruano. Conforme la CONAIE se iba incorporando a la vida política (Guerrero, 1995) a través de su protagonismo en diversas acciones de lucha, en el Perú, el otrora importante movimiento campesino se extinguía en medio de un olor a pólvora. Como se observa, la historia... de las poblaciones indígenas y/o rurales de estos tres países no han seguido necesariamente rutas paralelas, pero quizá la del Perú es la que más se diferencia. Sigue siendo complicado entender, cómo habiendo sido los quechuas ${ }^{l}$ el grupo étnico, político, económico y militar hegemónico durante el Imperio de los incas durante casi un siglo, no posean hoy día, en el Perú, ningún tipo de organización autónoma, o más aún, que no sea la nación o "nacionalidad" andina mejor organizada.

Uno de los objetivos más importantes de este trabajo será realizar una reflexión acerca de esta compleja realidad peruana, y tratar de aportar algunos elementos de juicio que puedan ayudar a su esclarecimiento futuro. También mostrará el itinerario del movimiento campesino peruano de las últimas décadas, épocas de gran convulsión política en las zonas rurales de esta parte de la región andina.

\section{De incas y de indios}

La crisis de la élite política incaica que apareció poco tiempo antes de la llegada de los españoles, constituye un hecho muy importante a la hora de intentar explicar la ausencia de una organización indígena "quechua" en la actualidad, descendiente de aquellos míticos incas. El conflicto suscitado entre los diversos grupos de poder existentes al interior de la élite incaica, con el tiempo, provocó la desaparición de esta clase gobernante, y con ello, la extinción del grupo quechua como nación.

Los quechuas fueron la nación integrada por varios grupos de cultura quechua, dirigidos por uno de ellos: los incas. 
Al no existir una élite inca que condujese a los quechuas, este grupo perdió su condición de nación, pasando nuevamente a la condición de etnia (Silva Santisteban, 1988)². Es posible en la actualidad encontrar todavía algunos pobladores de las comunidades de la sierra, especialmente cuzqueña, en esta situación.

A continuación, explicará algunas de las causas que provocaron el descabezamiento de la élite de la nación quechua, grupo dirigente que no ha podido reconstituirse hasta el día de hoy.

La élite política que gobernó el Imperio de los incas ${ }^{3}$, estuvo conformada principalmente por la nobleza cuzqueña. Fue la nobleza "de sangre" la que ocupó los cargos políticos, militares y religiosos más importantes. Estuvo integrada por las llamadas panacas ${ }^{4}$, que según algunos autores fueron once, aunque pudieron haber llegado a dieciséis de acuerdo a otras versiones. Cada nuevo Inca, al asumir el poder, dejaba de pertenecer a su panaca de nacimiento, y al morir sus descendientes conformaban una nueva panaca.

Según Miguel Cabello Balboa, en la época de la conquista solamente la panaca de Túpac Inca estuvo integrada por unos mil miembros (Conrad y Demarest, 1988). Esta cifra aproximada nos puede dar una idea sobre el tamaño de la nobleza de sangre.

El otro grupo de la clase gobernante lo constituyeron los ayllus cuzqueños, también llamados los ayllus custodios, que al parecer fueron diez y su función fue la de cuidar la ciudad del Cuzco, así como la de proteger al Inca (Rostworowski 1988, Pease 1991). Conforme el Tahuantinsuyu fue creciendo, fueron incorporándose a la élite política los curacas o jefes de las etnias conquistadas o controladas por los incas; así como los denominados curacas o incas de privilegio, los cuales eran elegidos por el Inca para la realización de trabajos específicos, generalmente de tipo burocrático-administrativo.

Se cree que fue la crisis y posterior desaparición de la élite política inca y quechua del Tahuantinsuyu, la que explica - en parte importante- la no articulación de movimientos indígenas quechuas en el Perú republicano y contemporáneo. La crisis política de la clase gobernante incaica se inicia, según algunos autores, en la época del inca Túpac Yupanqui (1471-1493), se desarrolla con Huayna Cápac y se desencadena en niveles de verdadero exterminio físico a partir de la guerra entre Huáscar y Atahualpa (Fernández, 1997).

El inicio de la conquista española y la era colonial, significaron la continuación de este proceso de liquidación de la élite incaica, no solamente de índole físico, sino también de tipo social, económico y político. En 1530, en el actual territorio del Perú existió una población aproximada de 9.000.000 de habitantes, cantidad que en el año de 1629 se vio reducida a 601.645 indios (Flores Galindo, 1988). Esta verdadera catástrofe demográfica, representa un

2 Silva Santisteban sostiene que "cuando en un grupo étnico emerge una élite conduciendo a las masas con base en un proyecto para constituir una entidad política propia, decimos que estamos en presencia de una nación".

3 Imperio también denominado el "Tahuantinsuyu".

4 Las panacas fueron una especie de ayllus reales o imperiales, es decir, clanes familiares descendientes de un Inca. 
elemento explicativo más para la comprensión del debilitamiento de los grupos étnicos peruanos, y en especial, el de la nación quechua.

En relación a la élite incaica, de acuerdo al censo que mandó a realizar el Virrey Toledo en 1572, en el Cuzco habían 1.294 nobles cuzqueños, treinta años más tarde, en 1602, sólo quedaban 567 miembros de las panacas de los incas (Espinoza, 1978).

\section{El surgimiento de la conciencia "india"}

Aparece cada vez con mayor nitidez la idea de que los diferentes grupos poblacionales, nacionalidades o etnias que habitaron el Tahuantinsuyu, no constituyeron propiamente una sola nación (quechua), que no se creó un sentimiento de pertenencia a un mismo grupo, o que nunca llegó a "cuajar" lo que hoy denominamos una identidad nacional. En el corto tiempo en que existió el Imperio de los incas -menos de un siglo-, sometió bajo su férula a centenares de grupos étnicos o "reinos pequeños", con los cuales estableció una relación de dominación, de pueblo conquistador/pueblo conquistado, de nación dominante/naciones o etnias dominadas.

Todo hace pensar que muchas de las naciones o etnias conquistadas no "sintieron" como "suya" o como "propia" a la cultura quechua ni a su clase dirigente incaica. Éstos fueron percibidos como unos jefes impuestos, extraños a su grupo porque sus jefes naturales eran sus curacas.

Fue recién después de medio siglo de dominación española que comenzó a surgir lo que podríamos llamar una identidad india en contraste con lo español: "apareció con claridad no sólo que los dominados eran los 'indios' y los dominadores los 'españoles”' (Burga, 1988), sino también que el sistema social del Tahuantinsuyu y su clase dirigente (los incas) fueron más justos y, por lo tanto, preferibles.

En este proceso de homogeneización de lo indio, es importante mencionar también, como factores convergentes, la catástrofe demográfica señalada en líneas anteriores, la adopción del quechua como lengua general para el adoctrinamiento cristiano, la política de extirpación de idolatrías y la creación de las reducciones de indios, fruto de las leyes del Virrey Toledo (Degregori, 1993).

Según afirman autores como Manuel Burga y Alberto Flores Galindo, fue a partir de esa época de desilusión — debido a los abusos cometidos por los españoles - cuando comenzó a surgir en la mente de los indígenas lo que han denominado la "utopía andina", es decir, una visión idílica y nostálgica del Tahuantinsuyu. Como producto

de la sedimentación de esta nueva visión, comenzaron a nacer movimientos indígenas con intenciones de reconstruir el sistema que imperó en el Tahuantinsuyu: la vuelta a un pasado idealizado.

Es posible pensar entonces, que debió ser la élite política incaica a la que le correspondió asumir este reto. Desgraciadamente -tal como la historia lo confirma-, la clase gobernante incaica no pudo, solamente, recomponerse 
y conducir con éxito la lucha por la reconstrucción del Imperio, sino que con el paso del tiempo se fue desmembrando hasta su desaparición como élite política.

Con la muerte de Manco Inca, cerca de 1545, se extinguió definitivamente la clase política incaica como grupo gobernante. El grupo de panacas cuzqueñas que apoyaron a Manco Inca, fue el último sector de la legendaria élite política incaica que actuó como grupo social dirigente organizado, cohesionado y legitimado por la tradición y su hegemonía.

La zona de Vilcabamba no fue solamente el escenario de la última actuación de los incas, sino también el lugar donde por última vez un grupo de dirigentes eminentemente indígena encabezó un movimiento político-militar masivo durante la colonia. Desde Manco Inca hasta nuestros días, no ha vuelto a existir una élite política indígena que dirija movimientos importantes de resistencia, independencia o liberación en el Perú. Todos los dirigentes importantes desde aquél entonces han sido mestizos (O'Phelan, 1995).

Las élites regionales del Tahuantinsuyu, encabezadas por sus curacas, ayudaron a los españoles a precipitar la derrota y desaparición de la élite incaica. Según Waldemar Espinoza (1990), los incas habrían conquistado cerca de doscientos reinos pequeños ${ }^{5}$ y de todos ellos "sabemos fehacientemente que el único señorío que luchó contra los españoles fue el del Cuzco, compuesto por los orejones incas”.

Estos señores étnicos, en su gran mayoría, no sólo fueron colaboracionistas, sino que además fueron una pieza clave en la estructura de gobierno de la colonia, porque fungieron de bisagra entre la administración española y sus poblaciones indígenas. Ya desde el siglo XVI, los curacas comenzaron a adoptar las formas de vida de los conquistadores: "imitaron su manera de vestirse, empezaron a montar a caballo, a portar armas europeas, a hablar castellano y hacer suya la dieta alimenticia traída del viejo mundo” (Burga, 1988). Sin embargo, el proceso de aculturación no fue total, como podría creerse. Los dos mundos permanecerán por muchos siglos en el subconsciente de estos señores, propiciando comportamientos frecuentemente ambiguos, así como un sincretismo cultural ${ }^{6}$.

Si bien una Real Cédula de 1790 propició un golpe mortal a los linajes étnicos, por eso fue apenas en las primeras décadas de instaurada la república del Perú cuando los curacas fueron borrados definitivamente del mapa, al ver eliminados sus títulos de nobleza por Bolívar en $1825 \mathrm{y}$, luego, ser reemplazados como poder local y como intermediarios entre las dos repúblicas (de indios y de españoles) por los prósperos hacendados serranos (gamonales) y los mistis (mestizos).

5 Según Conrad y Demarest (1988) citando a Rowe, sostienen que en el Tahuantinsuyu “..existían más de ochenta provincias, en las cuales vivían más de una tribu, y eso solamente en el Perú".

6 Estas contradicciones no impidieron que durante el siglo XVIII se dieran más de 128 rebeliones en el área andina: 10 en Ecuador, 107 en Perú y 11 en Bolivia 
Finalmente, para tratar de entender la dimensión del colapso que significó la destrucción de las élites incaicas, es relevante mencionar las consecuencias de la derrota de la gran rebelión indígena que dirigió Túpac Amaru II, mestizo ${ }^{7} \mathrm{y}$ descendiente de los incas, entre 1780 y 1781.

En el nivel político-social, se suprimieron los títulos de nobleza incaicos y se expropiaron muchas de las tierras y bienes de la nobleza quechua. Se eliminaron los curacazgos implicados en el levantamiento, así como también se abolió el carácter hereditario de todos los títulos de curaca (o cacique). En el nivel cultural, se prohibieron el uso del idioma quechua, las vestimentas nativas, el teatro y la pintura indígena, la lectura de los Comentarios Reales de Garcilaso de la Vega y se clausuró el colegio para curacas San Borja del Cuzco, entre otras medidas.

La profunda angustia que causó en el mundo español la posibilidad del triunfo de Túpac Amaru, trajo como resultado, asimismo, una concentración impresionante de milicias militares en el Virreinato del Perú, pues de 4.200 efectivos en 1760 se pasó a la suma de 70.000 combatientes en 1816. Esta ocupación militar debió haber influido en manera considerable en la sensación de opresión de los pueblos indígenas de ese entonces.

La conquista había significado una derrota atribuida en gran medida a factores "mágicos”, a una supuesta superioridad de los dioses cristianos sobre los dioses de los incas (Burga, 1988). A fines del siglo XVIII, en medio de una sociedad andina relativamente cristianizada, la derrota de Túpac Amaru ya no podía ser atribuida a los dioses. Esta nueva debacle probablemente reforzó aún más el sentimiento de inferioridad de los indios respecto a los blancos conquistadores. Una de las bases para la futura república pigmentocrática, se consolidó en este período. Pero, al mismo tiempo, como diría Flores Galindo (1988), "lo cierto es que el indio comienza a ser tan menospreciado como temido por quienes no lo son”.

\section{De indios a campesinos}

Iniciada la República, con la proclamación de la independencia en 1821, los indígenas del Perú vieron empeorar su situación. La guerra de liberación de España no solamente había creado un vacío de poder, sino además un caos en la estructura jurídico-administrativa, normal en estos tipos de transición de un sistema colonial a uno republicano. Lo cierto fue que hasta mediados del siglo XIX, en el Perú continuaron vigentes las leyes españolas, el tributo indígena y la esclavitud.

Fue en medio de esta inicial anarquía política y jurídica cuando numerosos mestizos y criollos aprovecharon la situación para apropiarse de tierras de las comunidades campesinas, amparados también por una legislación que desprotegió y liberalizó la tenencia y propiedad de las tierras comunales. Aunque parezca insólito, en la colonia se protegió más a la población indígena que en esta etapa auroral de la República (Belaunde, 1987). La declaración del castellano como el idioma oficial en 1825, constituyó un acto de segregación cultural. Esta medida fue rectificada después de 140 años.

7 Ya en el siglo XVIII gran parte de la nobleza nativa era mestiza y cristiana. 
El descontento no se dejó esperar: entre 1867 y 1868 se desarrolló la rebelión de Juan Bustamante, cuyo ejemplo fue imitado en gran parte por la zona sur del país, también conocida como "la mancha india" o el "trapecio andino".

En Puno y Cuzco se localizaron numerosas y endémicas rebeliones de indios entre 1886 y 1887, entre 1895 y 1906, en 1911, en 1913, en 1915, hasta llegar a la gran sublevación indígena que abarcó los departamentos de Cuzco, Puno, Arequipa, Ayacucho y Apurímac, entre 1920 y 1923. Esta sublevación provocó la invasión de muchas haciendas y el ajusticiamiento de varios gamonales (hacendados de la sierra). Después de esta experiencia, las relaciones entre los hacendados y los indígenas del sur no volvieron a ser las mismas (Burga y Flores Galindo, 1982).

El abandono y desprotección de la población indígena peruana, el aumento de los levantamientos que se venían dando en el sur, la revolución mexicana y más tarde la bolchevique, hicieron que desde fines del siglo XIX y comienzos del XX el tema del indio se fuera conviniendo en un problema nacional que debía ser resuelto de alguna manera.

Estos fueron algunos de los motivos que propiciaron el surgimiento del movimiento indigenista, el cual tuvo una producción artística e intelectual que marcó una época. Según José Tamayo (1981), el indigenismo llegó a su máximo esplendor entre los años de 1926 y 1930, después de este período se inició su rápido declive.

El indigenismo fue promovido desde el Estado y por el presidente Augusto B. Leguía (1919-1930) quien, hasta 1923, mantuvo una apertura política que permitió el crecimiento de diversos movimientos sociales. El mismo Presidente creó en 1922 el Patronato de la Raza Indígena. Surgieron durante su primer mandato varias organizaciones proindígenas, las cuáles, años más tarde, fueron disueltas por el propio Leguía.

Es muy probable que el discurso populista proindígena de Leguía abonara el terreno para el desencadenamiento del levantamiento indígena del sur del país entre 1920 y 1923. El incumplimiento de sus promesas electorales fue generando la difusión de movimientos de protesta que terminaron por desbordar la capacidad de control del Estado. Se hizo necesario el viraje hacia un sistema autoritario.

Los creadores y difusores del indigenismo no fueron indios, tanto en Cuzco y en Puno como en Lima, estuvo integrado por miembros de las clases medias provincianas (ya descontentas con el centralismo) o por sectores de la aristocracia limeña, ligada de alguna manera a la oligarquía, salvo en el caso de José Carlos Mariátegui.

El indigenismo nunca llegó a constituirse como un movimiento de masas. El mismo Estado que propició su vuelo al poco tiempo le cortó las alas.

8 Mirko Lauer sostiene que el "indigenismo socio-político aparece en la resaca depresiva de la guerra con Chile, cuando पquizás por un instante- tambalea la idea criolla de nacionalidad". Luis Monguió sostiene que "los peruanos que propusieron el indianismo cien por cien, respondían así a la necesidad de reivindicar ante sus propios ojos la parte india de su (propia) composición étnica" (Lauer, 1997). 
Un buen sector de los indigenistas, sobre todo cuzqueños, fue cooptado por el socialismo limeño, donde sobresalían las figuras de Haya de la Torre y José Carlos Mariátegui.

En 1927, parte del grupo de indigenistas cuzqueños organizaron una célula aprista, la cual al año siguiente se pasaría al partido socialista de Mariátegui (Sulmont 1985). Fueron los socialistas peruanos los que 'transformaron' a los indios en campesinos. Mirko Lauer, con razón, sostiene que este proceso de cambio de denominación fue una "construcción", que implicó un esfuerzo por redefinir a los mismos sujetos desde otra perspectiva conceptual (Lauer, 1997).

El socialismo no solamente es una visión del mundo y una interpretación de las relaciones sociales, es también una guía para la acción política de la clase trabajadora. Y a la clase trabajadora se la distingue de acuerdo a la actividad que realiza al interior del proceso productivo, o por el tipo de trabajo que desempeña.

Desde esta perspectiva, a los trabajadores se les clasificaba fundamentalmente como obreros o campesinos y no como blancos o indios. A partir de entonces, al indio que trabajaba en el campo se le empezó a llamar campesino. Este cambio se oficializará cincuenta años más tarde, en la década del 70, cuando el gobierno del general Juan Velasco modificó el nombre del Día del Indio por el Día del Campesino.

Se puede terminar diciendo que Mariátegui no aceptó esta división ortodoxa, que implicaba de cierta manera adherirse a una definición u otra: o indio o campesino. Para él no hubo una relación de exclusión entre estas dos formas de definir a los mismos sujetos. Eran las dos cosas: indios y campesinos.

Contrariamente a los dik-tak del comunismo moscovita, Mariátegui incluyó en sus descripciones, análisis y propuestas políticas la variable indígena, en sus connotaciones culturales, raciales, económicas y políticas que el marxismo internacional rechazaba. Esto le granjeó enemistades y marginaciones al interior del movimiento comunista internacional. A su muerte, el Partido Comunista (antes Socialista) aceptó las tesis de Moscú. La cita que se cree y se defiende en este artículo ilustra, en parte, lo que se transcribe a continuación:

"La reivindicación que sostenemos es la del trabajo. Es la de las clases trabajadoras, sin distinción de Costa y Sierra, ni de índio y cholo. Sí en el debate —esto es en la teoría- diferenciamos el problema del índio, es porque en la práctica, en el hecho, también se diferencia” (Mariátegui, 1927a)"

"El socialismo ordena y define las reivindicaciones de las masas, de la clase trabajadora. Y en el Perú las masas -la clase trabajadora- son en sus cuatro quintas partes indígenas. Nuestro socialismo no sería, pues, peruano -ni sería siquiera socialismo- si no se solidarizase, primeramente, con las reivindicaciones indígenas... Y en este 'indigenismo' vanguardista... no existe absolutamente ningún calco de 'nacionalismo exótico', no existe, en todo caso, sino la creación de un 'nacionalismo peruano' “ (Mariátegui, 1927b). 


\section{El movimiento campesino}

A partir de las décadas de los 30 y 40 del siglo XX, las distintas acciones que desarrollaron los campesinos estuvieron ligadas, de alguna manera, ya sea al Partido Aprista Peruano (PAP) o al Partido Comunista (PC). El PAP incorporó a los campesinos en su partido de Frente Único de clases, junto a la clase media y a los obreros (Haya de la Torre, 1936). Por su lado, el PC también incluyó en su política de alianzas a la clase campesina para ir formando con el tiempo, una sólida alianza obrero-campesina capaz de realizar la revolución proletaria en el Perú.

Si en 1786 la población mestiza era del 23\%, en 1940, de acuerdo al último censo que incluyó la categoría racial, la población mestiza y blanca sumaba más del $53 \%$, sin contar a los asiáticos y a los negros. A mediados del siglo XX, estamos ya frente a un país mayoritariamente mestizo, pero con una tendencia marcada hacia lo indomestizo. Las posteriores migraciones y procesos de urbanización han aumentado esta tendencia hacia el mestizaje.

Así como la apertura democrática del sistema político entre 1919-1925 permitió la aparición de importantes actos de movilización campesina y de creación artística e intelectual, la llegada al poder del presidente Luis Bustamante y Rivero (1945-48) con apoyo del aprismo, posibilitó nuevamente que los diferentes movimientos populares pudieran expresar sus demandas e intentar legalizar sus organizaciones.

En efecto, fue muy significativa la cantidad de sindicatos agrarios y comunidades campesinas que se legalizaron en el gobierno de Bustamante. Los niveles de movilización campesina, tanto en la Sierra como en la Costa, fueron de los más altos de la historia del Perú hasta ese entonces (Mejía, 1978). Las huelgas en la Costa y las invasiones de tierras en la Sierra generaron las condiciones para la creación de la Federación General de Yanaconas y Campesinos del Perú, en 1947. Más tarde, se crearían la Federación Nacional de Campesinos del Perú (FENCAP) y la Confederación Campesina del Perú (CCP).

El sistema político autoritario que reinstaura la dictadura del general Odría (1948-1956) trajo inicialmente como consecuencia un reflujo del movimiento campesino. Pese a ello, desde 1950 hasta 1964 se pudo apreciar una gran movilización campesina a lo largo y ancho del territorio nacional, simultáneamente con una oleada de venta de tierras por parte de los hacendados (1950-60), que hizo presagiar temporadas tormentosas en el sector agrario.

Entre 1956 y 1964, ya bajo el gobierno democrático de Manuel Prado (1956-62) es posible identificar hasta 413 movimientos campesinos, y sólo en el año de 1962 se pueden contar más de 70 haciendas invadidas (en su mayoría, movimientos de recuperación de tierras arrebatadas por los hacendados). El movimiento más importante se dio en los valles cuzqueños de Lares y la Convención, entre 1956 y 1962, coincidiendo exactamente con el período de gobierno de apertura democrática de Prado.

El líder más importante de este movimiento fue Hugo Blanco, mestizo, con estudios universitarios en Argentina y de inspiración trotskista, quien alentó con éxito la sindicalización, las huelgas y las invasiones para recuperar las tierras ex-comunales en dichos valles cuzqueños (Burga y Flores Galindo, 1982). El eco del triunfo de 
la Revolución Cubana en 1959, contribuyó al afianzamiento de la presencia de los partidos marxistas al interior del movimiento campesino.

Desde ese entonces hasta la irrupción armada de Sendero Luminoso (Partido Comunista del Perú) en 1980 y la del Movimiento Revolucionario Túpac Amaru (MRTA) en 1982, la influencia del marxismo en el movimiento campesino fue permanente.

La idea sobre la necesidad de una reforma agraria que hiciera justicia en el campo, empezó a ser difundida desde comienzos del siglo XX principalmente por el APRA (Alianza Popular Revolucionaria Americana), los socialistas y los comunistas, pero también posteriormente por los grupos reformistas socialcristianos y el progresismo en general.

El presidente Manuel Prado (1956-1962) nombró una comisión de alto nivel con el objetivo de elaborar un proyecto de reforma agraria. Dicho proyecto estuvo listo en las postrimerías de su Gobierno y optó por no implementarlo. Su sucesor, Fernando Belaunde (1963-1968), prometió durante su campaña electoral promulgar la Ley de Reforma Agraria; una vez en el poder, no tuvo la capacidad política para implementarla.

La incapacidad de la élite política civil peruana en implementar una reforma agraria justiciera, pero también racional y económicamente viable, generó una serie de reacciones sociales, como fue el estallido de las guerrillas del Movimiento de Izquierda Revolucionaria-MIR y del Ejército de Liberación Nacional-ELN (1964-65) las que fueron derrotadas sin mayor problema. Otra consecuencia inmediata fue el golpe militar del Gral. Juan Velasco Alvarado, el 3 de octubre de 1968.

La reinstauración, una vez más, de un sistema político autoritario, de dictadura militar, hacía presagiar la repetición de experiencias militares anteriores. Velasco Alvarado sorprendió a "tirios y troyanos" al iniciar el proceso de reformas sociales y económicas más importantes en lo que va de la historia Republicana del Perú.

Después del Gobierno de Velasco, para bien o para mal, el Perú fue otro; pues la primera Ley de trascendencia que promulgó su Gobierno, fue la Ley de Reforma Agraria en 1969. Esta medida ha sido considerada como una de las más radicales que se hayan tomado en América Latina, quizá solamente comparada con la reforma agraria cubana.

Fue durante el septenato de Velasco (1968-1975) cuando se dio el proceso de democratización social más importante en el Perú. Paradójicamente, fue un gobierno autoritario el que entregó las mayores cuotas de poder político en el nivel local, ya sea a los campesinos de la Costa o de la Sierra. Las organizaciones campesinas (Ligas Agrarias) creadas desde el Estado reemplazaron o compartieron el poder local con los antiguos grupos dominantes en muchas zonas y rincones del país. Sólo este hecho abrió las puertas a una dinámica de cambio social que aún no terminamos de vislumbrar. 
En el aspecto cultural, el velasquismo desplegó una política dirigida a revalorizar la tradición andina y popular. Túpac Amaru, mestizo y revolucionario, fue uno de los símbolos de la reforma agraria y parte esencial de la parafernalia del régimen militar. La declaración del idioma quechua como lengua oficial del Estado, junto con el español, fue un reflejo de lo que se viene sosteniendo.

El historiador José Tamayo (1981) visualizó una tendencia neoindigenista a finales de la dictadura de Velasco. Este gobierno militar creó en 1971 el Sistema Nacional de Movilización Social (SINAMOS) con la intención de promover la creación de movimientos sociales de tipo gremial para poder estructurar y controlar, en cierto modo, el sistema político que desearon implantar en el Perú: la Democracia Social de Participación Plena (Guerra García, 1983). Este modelo implicaba la creación de instituciones de gobierno integradas por representantes de los diferentes gremios del país. Fue un proyecto de tipo corporativo, que antes ya había sido planteado, de otra manera, por intelectuales y políticos peruanos, tales como Víctor Andrés Belaunde y Haya de la Torre.

En esta dirección, el Gobierno creó sus "propias” organizaciones gremiales, pues en 1972 se fundó la Confederación Nacional Agraria (CNA), y en diciembre del mismo año la Central de Trabajadores de la Revolución Peruana (CTRP). Y en el mes de febrero de 1973 salió a la luz la novedosa Confederación Nacional de Comunidades Industriales (CONACI).

Al amparo del sector progresista del velasquismo — que dominó el poder durante gran parte del tiempo que duró dicho Gobierno- surgieron y crecieron numerosos movimientos sociales y se legalizaron una cantidad jamás vista de sindicatos en plazos bastante cortos (Tovar, 1982).

Respecto al movimiento campesino, el surgimiento de nuevas organizaciones y la expansión de las ya existentes, tampoco tuvo parangón en la historia del Perú. La Confederación Campesina del Perú (CCP) ${ }^{9}$ organizó sus III y IV Congresos Nacionales en los años 1970 y 1973, lo cual significó la reorganización y revitalización de este gremio que fomentó durante la década del 70 algunas tomas de tierras en la Sierra del Perú (Tovar, 1982). Tuvo una posición de confrontación al régimen militar, aunque algunos de sus partidos influyentes llegaron a plantear un "apoyo crítico" al velasquismo.

La Confederación Nacional Agraria (CNA) fue, sin lugar a dudas, la organización campesina más grande y representativa durante las décadas de los 70 y 80 en el Perú. Si bien su crecimiento se debió inicialmente al apoyo del Estado, a partir de 1976, después del golpe del Gral. Francisco Morales Bermúdez (1975-1980) fue declarada ilegal debido a su actitud de franca oposición al desmontaje de las reformas iniciado por el nuevo gobernante.

9 Integrada por dirigentes campesinos pertenecientes en su gran mayoría a partidos marxista-leninistas como el MIR, Vanguardia Revolucionaria, OC Bandera 
Legitimada por su representatividad, aunque ilegal aún, la $\mathrm{CNA}^{10}$ logró reorganizarse en el nivel nacional a partir de su masiva VII Asamblea Nacional de Delegados, realizada en Cajamarca en diciembre de 1980. Ya reactivada y con un nivel de autonomía política considerable - a diferencia de otros gremios - la CNA realizó su III Congreso Nacional en junio de 1982 (Junín), evento que contó con la participación de delegados de todos los gremios campesinos del Perú. Ya en esta época, la CNA se había convertido en el movimiento campesino más importante del país, con una orientación socialista y nacionalista capaz de convocar al conjunto de las organizaciones agrarias del país.

Es así como en octubre de 1982, la CNA convoca al resto de gremios campesinos para la realización de un Paro Nacional (huelga nacional). La mayoría y las más importantes de estas organizaciones ${ }^{11}$ aceptaron y se incorporaron al Comité Central de Acción, organizador de la medida de fuerza.

De esta manera se gestó y realizó el Primer Paro Nacional Campesino en la historia de la República del Perú. Entre el 25 y 26 de noviembre de 1982, la mayoría de los campesinos del Perú detuvieron sus labores y bloquearon gran parre de las carreteras del país (CIDIAG 1983). Al año siguiente se realizó el II Paro Nacional Agrario, con un nivel menor de contundencia.

Fue a partir de 1985 cuando el movimiento campesino entró en un proceso de repliegue, debido a que el Partido Comunista del Perú (Sendero Luminoso) y el Movimiento Revolucionario Túpac Amaru (MRTA) ya comenzaban a desplegar sus acciones armadas con mayor amplitud territorial, con el consiguiente proceso de militarización del espacio rural. La lógica de la guerra empezó a desplazar a la actividad política en las zonas rurales del Perú.

Esta situación provocó un debilitamiento de las organizaciones campesinas, las que ya habían perdido fuerza debido al proceso de parcelación o privatización de las cooperativas agrarias de producción, ubicadas principalmente en la costa.

De aquella época a la fecha, los procesos de parcelación, privatización y restauración de los latifundios, han recompuesto la estructura de propiedad y tenencia de la tierra. En este nuevo escenario agrario, las organizaciones campesinas de fines del siglo pasado no han podido aún recobrar su importancia gremial, fortaleciéndose en cambio otros tipos de asociaciones de agricultores, como las vinculadas al tema del manejo del agua de regadío (juntas de usuarios de los distritos de riego, juntas y asociaciones de regantes, etc.)

10 Los partidos políticos con mayor influencia en la CNA fueron el Partido Socialista Revolucionario (PSR), el Partido Comunista Peruano (PCP-Unidad) y el Partido Comunista Peruano (PCP-Mayoría, escisión del PCP-Unidad). Sin embargo, la CNA albergó a campesinos de todos los partidos políticos. Debido a la hegemonía de la CNA en el movimiento campesino en este período, los diversos partidos lucharon por "controlar" la dirigencia de la CNA, tratando de colocar dirigentes afines a sus respectivos partidos en la Junta Directiva, Federaciones Departamentales y Ligas Agrarias de dicha organización.

11 Firmaron la convocatoria de Paro Nacional Agrario, además de la CNA, la FENDECAAP ( Federación Nacional de Cooperativas Azucareras), la Confederación General de Campesinos del Perú (CGCP) y Comité de Defensa de la Pequeña y Mediana Agricultura (CODEAGRO). Luego se adhirieron otras organizaciones agrarias. 


\section{De campesinos a revolucionarios}

Como hemos podido apreciar en la breve reseña expuesta sobre la evolución del movimiento campesino, conforme el marxismo fue introduciéndose desde la década del 30 del siglo XX en la sociedad peruana, la percepción que se tenía del campesino se fue modificando poco a poco, convirtiéndose con el tiempo en un potencial "sujeto revolucionario", junto con el proletario.

La concepción de la necesidad de una alianza obrero-campesina como eje de la revolución proletaria en el Perú, con el andar de los años, comenzó a construirse $\square$ al interior de la izquierda marxista peruana $\square$ en una idea aceptada unánimemente. El habitante rural ya no era solamente un indio y un campesino, debía ser además un revolucionario, una clase revolucionaria con una misión histórica muy clara que cumplir: hacer la revolución y construir el socialismo en el Perú.

Esta transformación del campesinado en actor protagonista del proceso revolucionario se afianzará a partir de la ruptura del movimiento comunista internacional (China - Unión de Repúblicas Socialistas Soviéticas) a comienzos de la década del 60, hecho que provocará también en el Perú la división del Partido Comunista Peruano (Unidad) $^{12}$ prosoviético, y la aparición de otro Partido Comunista del Perú (Bandera Roja) pro-chino.

Debido al sesgo 'agrario' que Mao Tse-tung le imprimió a la revolución China, sus planteamientos se difundieron fácilmente en los países subdesarrollados, con poblaciones campesinas extensas y pobres como las del Perú.

El maoísmo plantea que en países agrarios y atrasados, el papel del campesinado pobre debe ser, de primer orden, en el proceso revolucionario, incluso más importante que el del proletariado. El campesinado pobre debía ser "el motor de la revolución".

La mayoría de los partidos (Letts 1981) con influencia en la CCP adoptaron esta posición respecto al papel del campesinado, pero quien mejor llevó a la práctica las enseñanzas de Mao Tse-tung fue el Partido Comunista del Perú (Sendero Luminoso).

Sendero Luminoso le declaró la guerra al Estado peruano en 1980. Reclutó para su causa a un alto porcentaje de campesinos $\square$ en su mayoría indígenas $\square$ de las alturas andinas, caracterizados por su pobreza y desconexión con el mundo de la información y educativo. Después de una primera etapa de expansión de este movimiento debido a su actuar justiciero, de acuerdo al decir campesino de esa época, Sendero comenzó a realizar una serie de

12 En el Perú existen varios "Partidos Comunistas del Perú", y sus siglas se diferencian de otras debido a que después de su nombre, se coloca entre paréntesis 
acciones demenciales y terroristas que fueron enfrentándolo no sólo con la opinión pública, sino con los propios dirigentes populares y campesinos de la izquierda revolucionaria ${ }^{13}$.

La presencia de Sendero (desde 1980) y el MRTA (desde 1982) en el campo por más de una década, obligó al movimiento campesino a replegarse y casi desintegrarse lentamente, hasta el presente.

Al desastre ocasionado en el agro, ya sea por una reforma agraria con errores e incompleta, o por la violencia de Sendero y el MRTA, se le sumó después la política neoliberal del presidente Fujimori, que no permitió la recuperación de este sector de la población peruana (sobre todo de la sierra pobre y andina).

\section{De revolucionarios a productores agrarios o agricultores}

El proceso de parcelación de las cooperativas agrarias ${ }^{14}$ de la costa provocó el reemplazo de los "campesinos cooperativistas" o de los socios de las cooperativas en parceleros ${ }^{15}$, ahora llamados agricultores o productores agrarios. Tanto el proceso de parcelación-privatización de las propiedades colectivas (cooperativas), así como la forzada despolitización en el campo producida por la guerra interna entre el Estado y Sendero-MRTA, ha ido transformando la realidad rural del Perú. Nuevos actores sociales, nuevas organizaciones agrarias, resurgimiento del latifundio, son algunas de la características que están redibujando las relaciones sociales, económicas y políticas en este importante y aún desatendido sector agrario del Perú.

\section{Algunas reflexiones finales}

En esta última parte del presente trabajo, quisiéramos decir que los movimientos sociales tradicionales o “viejos” (Linch 1999), como lo son el campesinado y el proletariado, se desarrollaron con mayor vigor cuando desde el Estado hubo políticas explícitas de apoyo en esta dirección, Y esto vale tanto para los gobiernos democráticos como para los autoritarios (Touraine, 1989).

Desde esta perspectiva, los movimientos sociales —y el campesino en especial— no solamente tuvieron una cierta dependencia con las políticas de apoyo estatal, sino que también su historia estuvo íntimamente ligada, o atada, al rumbo que siguieron los partidos políticos que ejercieron una influencia determinante en sus cuadros dirigentes. Cabe resaltar la influencia del aprismo, pero sobre todo de la izquierda marxista.

Hay que tener muy presente esta realidad a la hora de analizar el papel de los movimientos sociales en los procesos políticos del siglo XX en el Perú, incluidos los de transición a la democracia y al autoritarismo.

13 El ajusticiamiento cruel e insano de la querida e izquierdista dirigenta barrial de Lima María Elena Moyano, marcó el momento de inflexión definitivo de Sendero. A partir de este irracional acto terrorista, se puede vislumbrar con mayor nitidez el camino hacia el ocaso de este movimiento político.

14 Las cooperativas agrarias de productores y de servicios cubrieron gran parte del territorio de la costa peruana, y en menor medida de la sierra y la selva.

15 Los parceleros recibieron generalmente alrededor de tres hectáreas cada uno, por lo menos. 
Habría que señalar que la izquierda marxista de finales de la década del 70 del siglo pasado, heredera del pensamiento mariateguista e indigenista, empezó a incluir en su discurso político el tema de los derechos de las nacionalidades originarias como parte de las reivindicaciones por las cuales había que movilizar al pueblo. Al poco tiempo, en 1980, la lucha armada comenzó a expandirse en el campo peruano, bloqueando toda posibilidad de seguir ‘imaginando comunidades étnicas'.

Finalmente, es importante señalar que a comienzos del siglo XXI el Perú sigue siendo una República pigmentocrática. Pese a los cíclicos esfuerzos desde el Estado y desde la sociedad civil por revalorizar lo indio, la construcción de la identidad nacional no valora aún en su debida dimensión este legado cultural ${ }^{16}$, no sólo por las razones expuestas en este trabajo, sino porque todavía en el imaginario de la población india e indomestiza actual, existe una visión alienada de las culturas y razas indígenas: todo lo relacionado con "lo indio" es sentido, percibido, todavía, como algo inferior.

La memoria histórica hace aparecer al indígena como el conquistado-derrotado, el siervo, el pobre, e incluso el que tiene un nivel menoscabado de autoestima estética.

Felizmente, esta tendencia se ha ido modificando en la última mitad de siglo XX y en lo que va del XXI. Este proceso sigue en curso, lo cual es importante, ya que la contribución cultural y racial de lo indio en el Perú, ha sido, es y será uno de los pilares de la construcción de la identidad nacional peruana. Por otro lado, se sabe que la autoestima de un pueblo es la base indispensable para el proceso de desarrollo de cualquier país.

16 La construcción de la identidad nacional también se ha estado gestando a través del desarrollo de "identidades" regionales, clasistas y ciudadanas, lo cual según Degregori (1993) puede evitar "los callejones sin salida a los cuales parece conducir la preeminencia unilateral de las identidades étnicas en otras partes 


\section{Referencias}

1. Belaunde, Víctor Andrés (1987). Meditaciones peruanas, Obras Completas, Tomo II, Lima: Comisión Nacional del Centenario.

2. Burga, Manuel y Alberto Flores Galindo (1982). Feudalismo Andino y Movimientos Sociales (1866- 1965). En: Historia del Perú, tomo XI, Barcelona: Editorial Mejía Baca.

3. Burga, Manuel (1988). Nacimiento de una utopía. Muerte y resurrección de los incas. Lima: Instituto de Apoyo Agrario.

4. Calla Ortega, Ricardo (1993). Hallu huayllisa huti. Identificación étnica y proceso político en Bolivia. En: Democracia, etnicidad y violencia política en los países andinos. pp.: 57-81, Lima: Instituto Francés de Estudios Andinos (IFEA) e Instituto de Estudios Peruanos (IEP).

5. CIDIAG (1983). Paro nacional agrario. Histórica lucha del movimiento campesino. Lima: Centro de Información y Desarrollo Internacional de Autogestión.

6. Conrad, Goeffrey y Arthur A. Demarest (1988). Religión e imperio. Dinámica del expansionismo azteca e inca. Madrid: Alianza Editorial.

7. Degregori, Carlos Ivan (1993). Identidad étnica, movimientos sociales y participación política en el Perú. En: Democracia, etnicidad y violencia política en los países andinos. Lima: Instituto Francés de Estudios Andinos e Instituto de Estudios Peruanos, pp.: 113-133.

8. Espinoza Soriano, Waldemar (1978). Los modos de producción en el imperio de los incas. Lima: Editorial Mantaro.

9. (1990). La destrucción del imperio de los incas. Lima: Amaru Editores.

10. Fernández Fontenoy, Carlos (1997). La élite política incaica: el derrotero de una crisis. Lima. IUS ET PRAXIS, 27: 89-101

11. Flores Galindo, Alberto (1988). Buscando un inca. Lima: Editorial Horizonte.

12. Guerra García, Francisco (1983). Velasco: del Estado oligárquico al capitalismo de Estado. Lima: CEDEP

13. Guerrero, Andrés (1993). De sujetos indios a ciudadanos-étnicos: de la manifestación de 1961 al levantamiento indígena de 1990. En: Democracia, etnicidad y violencia política en los países andinos. Lima: Instituto Francés de Estudios Andinos e Instituto de Estudios Peruanos, pp.:83-101.

14. Haya de la Torre, Víctor Raúl (1936). El antiimperialismo y el APRA. Santiago de Chile: Editorial Ercilla.

15. Letts, Ricardo (1981). La izquierda peruana. Lima: Mosca Azul Editores. 
16. Lauer, Mirko (1997). Andes imaginarios. Discurso del indigenismo. Cuzco: Centro de Estudios Regionales Andinos "Barrolomé de las Casas".

17. Lynch, Nicolás (1999). Una tragedia sin héroes: La derrota de los partidos y el origen de los independientes en el Perú 1980-1992. Lima: Fondo Editorial de la Universidad Nacional Mayor de San Marcos. 79 p.

18. Mariátegui, José Carlos (1927). Réplica a Luis Alberto Sánchez. En: La polémica del indigenismo. Recopilación de Manuel Aquézolo, 1976. Lima: Mosca Azul Editores.

19. (1927). Intermezzo polémico. En: La polémica del indigenismo. Recopilación de Manuel Aquézolo. 1976, Lima: Mosca Azul Editores.

20. Mejía, José Manuel (1978). El movimiento campesino en el Perú. Análisis. Lima, 5: 93-99.

21. O’Phelan Godoy, Scarlett (1995). La gran rebelión en los Andes: de Túpac Amaru a Túpac Catari. Cuzco: Petroperú y Centro Bartolomé de las Casas.

22. Pease G.I., Franklin (1991). Los incas. Lima: Pontificia Universidad Católica del Perú, pp.:114-115.

23. Rostworowski. María (1988). Historia del Tahuantinsuyu. Lima: Instituto de Estudios Peruanos, pp.: 35-36, 183.

24. Silva Santisteban. Luis (1988). Estado, proyecto histórico y sistema internacional. Revista Peruana de Ciencia Política y Ciencias Sociales. Lima: Editorial Perla, 1 :215-282.

25. Sulmont, Denis (1985). El movimiento obrero peruano (1890-J980). Lima: Editorial Tarea.

26. Tamayo Herrera, José (1981). El pensamiento indigenista. (Antología), Lima: Mosca Azul. Editores.

27. Touraine, Alain, (1989). América Latina: política y sociedad Madrid: Editorial Espasa-Calpe, pp.: 162-163.

28. Tovar Samanez, Teresa (1982). Velasquismo y movimiento popular. Lima: DESCO 
Listado de evaluadores. Panorama 11. Volumen VI, Número 2. (Julio-Diciembre 2012)

Cecilia Rincón Verdugo

Universidad Distrital Francisco José de Caldas

Máster en Estructuras y procesos del aprendizaje

José Guillermo Martínez Rojas

Pontificia Universidad Javeriana

Magister en Educación

Gloria Calvo

Universidad Pedagógica Nacional de Colombia

Licenciada en Psicología

Jorge Alberto Portillo Chávez

Universidad Tecnológica de EI Salvador

Máster en Ciencias de la Información y Gestión

del Conocimiento

Isabel Hernández Arteaga

Universidad Cooperativa de Colombia

Doctora en Ciencias de la Educación
Yolanda Ladino Ospina

Universidad Pedagógica Nacional

Doctora en Educación

Surgei Bolivia Caicedo Villamizar

Universidad de Pamplona

Doctora en Ciencias Pedagógicas

Giovanny Cardona Montoya

Fundación Universitaria CEIPA

Doctor en Ciencias Pedagógicas

Edna Patricia Lopez Pérez

Universidad Pedagógica

Magister en Desarrollo Educativo y Social

Alexander Ortiz Ocaña

Universidad del Magdalena

Doctor en Ciencias Pedagógicas

Ana Patricia León Urquijo

Universidad de Los Lagos

Doctora en Filosofía y Ciencias de la Educación

Sebastián Romero Buj

Asesor Independiente

Licenciado en Educación 